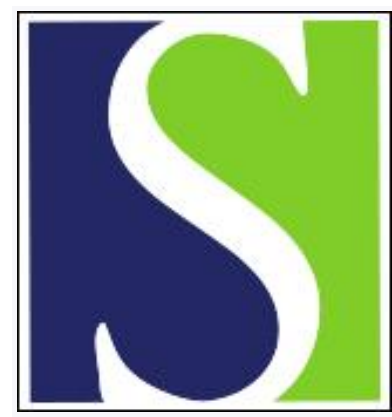

Scand J Work Environ Health 2013;39(5):515-520

https://doi.org/10.5271/sjweh.3356

Published online: 14 Mar 2013, Issue date: 01 Sep 2013

Working hours and depressive symptomatology among full-time employees: Results from the fourth Korean National Health and Nutrition Examination Survey (2007-2009)

by Kim I, Kim H, Lim S, Lee M, Bahk J, June KJ, Kim S, Chang WJ

We found an association between long working hours and depressive symptomatology. The full-time employees who worked long hours showed higher prevalence of depressive symptomatology after the data were adjusted for individual characteristics, socioeconomic factors, health behaviors, and work schedules.

Affiliation: Department of Preventive Medicine, Ewha Woman's University School of Medicine. 911-1, Mok-6-dong, Yandchun-gu, Seoul, Korea. hj7121@gmail.com

Refers to the following texts of the Journal: 2003;29(3):171-188 2009;35(5):361-367 2011;37(5):402-410 2012;38(5):418-426

The following articles refer to this text: 2016;42(2):135-143; 2020;46(5):480-487

Key terms: depression; depressive symptomatology; full-time employee; Korea; Korean National Health and Nutrition Examination Survey; mental disorder; mental health; mental illness; workhour; working hour; worktime

This article in PubMed: www.ncbi.nlm.nih.gov/pubmed/23503616

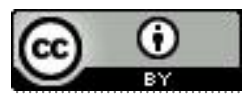




\title{
Working hours and depressive symptomatology among full-time employees: Results from the fourth Korean National Health and Nutrition Examination Survey (2007-2009)
}

by Inah Kim, MD, PhD, ${ }^{1}$ Hyunjoo Kim, MD, PhD, ${ }^{2}$ Sinye Lim, MD, PhD, ${ }^{3}$ Mira Lee, MD, ${ }^{4}$ Jinwook Bahk, $M P H,{ }^{5}$ Kyung Ja June, PhD, ${ }^{6}$ Soyeon Kim, MPH, Won Joon Chang, MD ${ }^{8}$

Kim I, Kim H, Lim S, Lee M, Bahk J, June KJ, Kim S, Chang WJ. Working hours and depressive symptomatology among full-time employees: Results from the fourth Korean National Health and Nutrition Examination Survey (2007-2009). Scand J Work Environ Health. 2013;39(5):515-520. doi:10.5271/sjweh.3356

\begin{abstract}
Objective This study aimed to examine the distribution of working hours and the association between working hours and depressive symptomatology using representative data from a national, population-based survey.

Method Data came from the fourth Korean National Health and Nutrition Examination Survey (2007-2009), which employed a systematic, stratified cluster-sampling method. We used logistic regression procedures to estimate the importance of weekly working hours as a predictor of depressive symptomatology.

Results The prevalence of depressive symptomatology was $10.2 \%$. The work week, which averaged 48.3 hours for the sample as a whole, was longer for men (49.8 hours) than women (45.3 hours), and $12.1 \%$ of respondents were engaged in shift work. In logistic regression analyses, compared to those working $<52$ hours per week, the odds ratios (OR) of working hours as a predictor of depressive symptomatology were 1.19 [95\% confidence interval (95\% CI) $0.77-1.85$ ] for those working 52-59 hours per week and 1.62 (95\% CI 1.20-2.18) for those working $\geq 60$ hours per week, after adjustment for demographic characteristics, health behaviors, socioeconomic status, employment status, and work schedules. It showed a positive dose-response relationship between working hours and depressive symptomatology $(\mathrm{P}=0.0059)$.
\end{abstract}

Conclusions Working hours in Korea are long. There is an association between working hours and depressive symptomatology, and there seems be a trend in working hours and depressive symptomatology.

Key terms depression; Korea; mental disorder; mental health; mental illness; workhour; worktime.

Long working hours increase the risk of various health problems, such as coronary heart diseases, work-related injuries, sleep disorders, and mental disorders (1-3). Work schedules can affect the length and quality of sleep, leading to low productivity and workplace hazards. Likewise, long working hours can cause other medical problems, including fatigue, excessive stress, negative mood, generalized discomfort and pain as well as neurological, cognitive, and physiological dysfunction (4).
The World Health Organization has predicted that depression will account for the second largest proportion of global disease burden by 2020 (5). Depression could deteriorate industrial productivity and reduce cost effectiveness $(6,7)$. Mood disorders have emerged as the second most common psychiatric disorder compensated by the Industrial Accident Compensation Insurance (IACI) in Korea, followed by neurotic, stress-related, and somatoform disorders (8).

\footnotetext{
1 Department of Occupational Health, Graduate School of Public Health, Yonsei University, Seoul, Korea.

2 Department of Preventive Medicine, Ewha Woman's University School of Medicine, Seoul, Korea

3 Department of Occupational and Environmental Medicine, Kyung hee University Hospital, Seoul, Korea.

4 Physicians For Humanism, Loves Park, IL, USA.

5 Department of Occupational \& Environmental Health, Graduate School of Public Health, Seoul National University, Seoul, Korea.

6 Department of Nursing, Soonchunhyang University, Cheonan, Korea.

7 Department of Health Science and Services, Graduate School of Public Health, Seoul National University, Seoul, Korea.

8 Department of Occupational and Environmental Medicine, Dankook University Hospital, Cheonan, Korea.
} 
Several studies have shown inconsistent relationships between long working hours and depression (9-12). Inconsistencies between studies might originate from small sample sizes, study subjects that are limited to specific organizations or occupations, cross-sectional study designs, or various methods for evaluating working hours or depression (13-15).

Koreans work long hours. In 2010, annual working hours in Korea averaged 2193 hours per person, the highest among the Organization for Economic Cooperation and Development (OECD) countries (16). In $2004-2005,49.5 \%$ of the workers spent $>48$ hours in the workplace, the second-highest figure in the world after Peru (17).

Despite these observations, research on the relationship between working hours and mental health has remained very limited in Korea and other countries. This study aimed to (i) examine the distribution of working hours among Korean workers, using representative data from a large national survey, and (ii) investigate the relationship between working hours and depressive symptomatology.

\section{Methods}

\section{Study subjects}

This study was based on representative data obtained from the fourth Korean National Health and Nutrition Examination Survey (K-NHANES IV), conducted by the Ministry of Health and Welfare since 1998. K-NHANES IV uses a systematic, stratified, cluster-sampling procedure based on the 2005 National Census Registry, and a rolling sampling survey method was introduced in the same year. This approach made each sample conducted over a 3-year time period an independent and homogeneous probability sample. The response rate for K-NHANES IV was 78.4\%. Of the 24871 people who participated in the health interview survey (4594 in 2007, 9744 in 2008, and 10533 in 2009), 4662 fulltime employees (FTE) working $>35$ hours per week were included in our study.

\section{Study variables}

\section{Demographic and behavioral characteristics}

Information regarding gender, age, marital status, alcohol consumption, smoking status, and exercise was obtained through interviews. "Problem drinking" was defined as consuming $\geq 6$ and 4 glasses of alcohol $\geq 2$ times per week among men and women, respectively. Exercise was defined as physical exercise for $\geq 20 \mathrm{~min}$ utes $\geq 3$ times per week that led to rapid respiration or physical strain.

\section{Working hours and work schedules}

Working hours were identified using the following question: "How many hours do you work in a week on average in your job, including overtime but excluding meal time?" We classified working hours into three categories: (i) $<52$ hours, (ii) $52-59$ hours, and (iii) $>60$ hours per week. This classification is based on the fact that 52 hours per week is the working hour limit suggested in the Labor Standard Act in Korea (18), and 60 hours per week is the practical standard of the Korean government for compensation of death caused by overwork.

Those who answered "yes" to the question, "Do you usually work during the day time (6:00-18:00 hours)?" were classified as day workers, while those who answered "no" were classified as shift workers.

\section{Depressive symptomatology}

FTE were defined to have depressive symptomatology if they answered positively to the question, "Have you experienced serious sadness or hopelessness that restricts your daily life, continuously for $\geq 2$ weeks in the last year?"

\section{Statistical analysis}

We used SAS software package version 9.2 (SAS Institute, Cary, NC, USA) to estimate means, proportions, and adjusted odds ratios (OR) for multi-stage and stratified survey design. We adapted the integrated survey weights according to the official analysis guidelines of the Korea Ministry of Health and Welfare and the Korea Center for Disease Control and Prevention. We additionally used the Cochran-Armitage trend test to examine a dose-response association between working hours and the OR.

\section{Results}

\section{Demographic and work characteristics}

More male (65.9\%) than female (34.1\%) FTE participated in this study to reflect the gender distribution among Korean workers in the general population. The majority of respondents $(52.9 \%)$ belonged to age group 20-39 years old, followed by $40-54$-year olds $(35 \%)$, $\geq 55$-year olds $(10.5 \%)$, and $<20$-year olds $(0.9 \%)$. 
The total number of weighted study population was approximately 11.9 million. Of the FTE, $36.0 \%$ were current smokers, $22.7 \%$ were problem drinkers, and $78.4 \%$ were regular workers whose work contracts lasted for $\geq 12$ months. With respect to working hours per week, $61.0 \%$ worked $<52$ hours, $9.0 \%$ worked $52-59$ hours, and $20.6 \%$ worked $\geq 60$ hours. Of the FTE, $12.1 \%$ were engaged in non-daytime shifts, including evening or night shifts. The prevalence of depressive symptomatology among FTE was $10.2 \%$ (table 1).

\section{Weekly working hours and depressive symptomatology}

The work week was longer among men [49.8, standard error (SE) 0.3, hours] than women (45.3, SE 0.4, hours). The work week was the longest among participants aged 20-39 years (48.9, SE 0.3, hours). For women, working hours were the longest among divorced, separated, or widowed participants (46.5, SE 1.2, hours). Current smokers and problem drinkers showed longer working hours (50.3 hours and 49.6 hours, respectively), and the differences between smokers versus non-smokers and problem drinkers versus non-problem-drinkers were larger among women than men. According to employment status, day laborers who work for daily wages worked shorter hours (42.6, SE 1.1, hours) than regular (48.9, SE 0.3, hours) or temporary workers (48.4, SE 0.8 , hours). The working hours of FTE in 24-hour rotating shifts were the longest (68.9, SE 3.0, hours) compared to other categories of shifts. FTE who experienced depressive symptomatology worked longer hours (49.2, SE 0.8 , hours) than non-depressed respondents (table 2).

\section{Multivariate analysis of working hours and depressive symptomatology}

Model 1 was adjusted for age, gender, marital status, and education status. The reference group comprised FTE who worked $<52$ hours per week. As a predictor of depressive symptomatology, the OR for working $\geq 60$ and 52-59 hours per week was 1.46 (95\% CI 1.12-1.90) and 1.23 (95\% CI $0.85-1.79)$, respectively. After further adjustment for health behaviors such as smoking, drinking, and exercise in model 2, the OR for working $\geq 60$ and 52-59 hours per week was 1.63 (95\% CI 1.22-2.17) and 1.23 (95\% CI $0.82-1.85)$, respectively. In model 3 , additionally adjusted for employment status and working schedules, the OR for working $\geq 60$ and 52-59 hours per week was 1.62 (95\% CI 1.20-2.18) and 1.19 (95\% CI $0.77-1.85$ ), respectively. We also found that the relationship between working hours and depressive symptomatology showed a dose-response relationship ( $\mathrm{P}$-value for trend test $=0.0193,0.0039$, and 0.0059 , respectively). However, we could not find a relationship between shift work and depressive symptomatology (OR
$1.01,95 \%$ CI $0.71-1.42$ ) (table 3 ).

\section{Discussion}

In this study using representative national data, we confirmed that the working hours in Korea are substantially longer than most OECD countries. Approximately 20\% of the FTE worked $\geq 60$ hours per week as compared to $9.5 \%$ in Australia in 2000 (20). The average work week of FTE in Korea (48.3 hours) was longer than the average work week of the 27 European Union (EU27) member states in 2006 (41.3 hours) (21). In the European Working Condition Survey, some 15\% of employees in the EU27 worked $\geq 48$ hours per week. In the Nordic countries, $<10 \%$ of the workforce worked $>48$ hours per week. The Korea Workers Compensation \& Welfare Service considers that a work week of $\geq 60$ hours warrants compensation as it contributes to "death by overwork."

We also found a substantial relationship between working hours and depressive symptomatology, which is consistent with previous studies. Virtanen et al (12) found that working $>55$ hours per week is associated with depressive symptoms; a cohort study using Whitehall II data revealed that every 10 -hour increase in working hours is related to a $17 \%$ increase in depressive symptoms (12).

Our study is the first to identify the association between working hours and depressive symptomatology using representative national data in Korea. As revealed by the significant trend showing higher level of depressive symptomatology among respondents working $\geq 60$ hours per week as compared to those working $<60$ hours, we can also suggest the possibility of dose-response relationship between long work weeks and depressive symptomatology.

Although we used survey analysis with suitable weighting procedures to estimate the association between working hours and depressive symptomatology among Korean workers, the actual number of FTE respondents remained relatively small. Cross-sectional design is another limitation of the study. Due to lack of longitudinal follow-up data, definite conclusions about causality between working hours and depressive symptomatology could not be drawn. That is to say, reverse causality between work hours and depressive symptomatology could not be ruled out. In addition, the K-NHANES IV uses a single question to assess depressive symptomatology; a stronger procedure should involve a multi-item, validated instrument to identify depression.

In this study, the relationship of work schedule and depressive symptomatology proved no significance, unlike previous studies showing an association 
Table 1. Characteristic of study subject $(\mathrm{N}=4662)$. [ $\mathrm{SE}=\mathrm{standard}$ error]

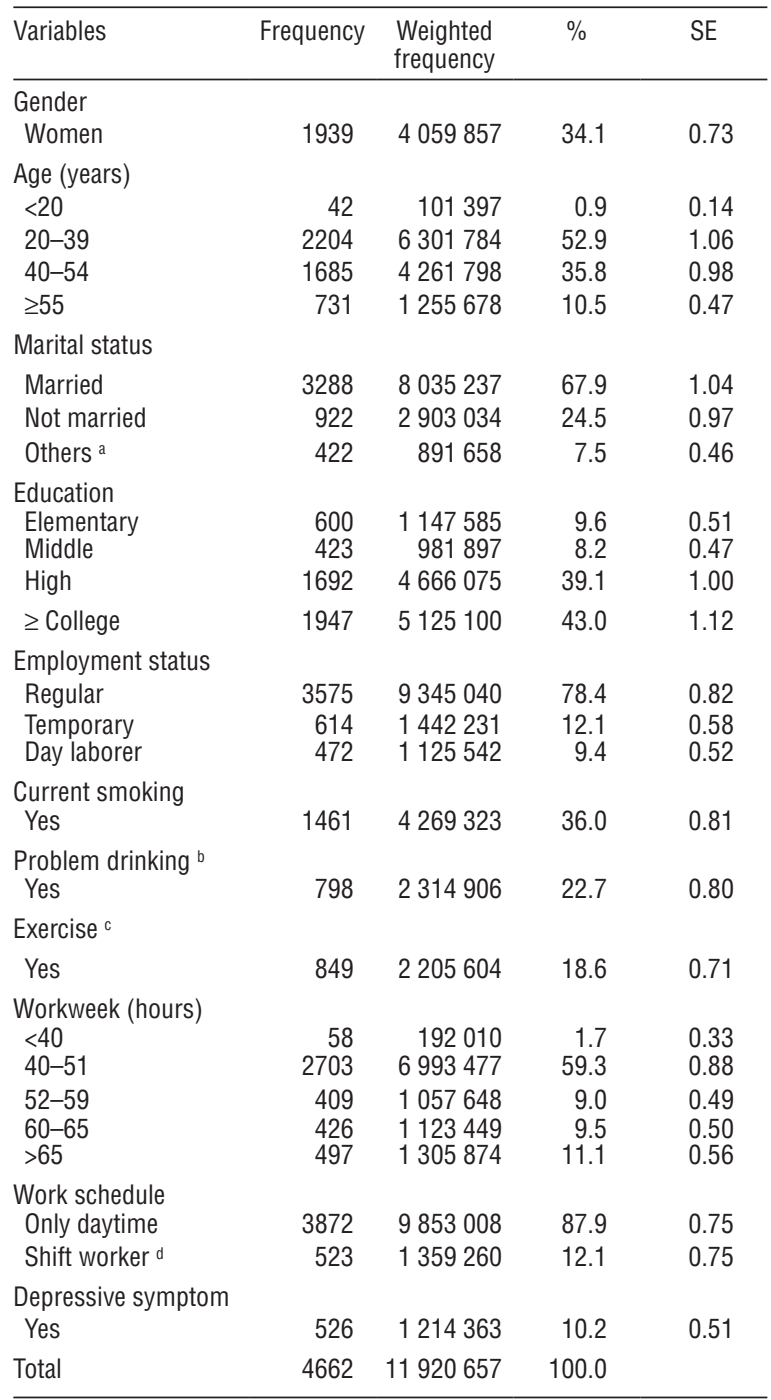

a Widowed, separated, or divorced

b Average amount in each kind of drinking was $\geq 6$ units for men and $\geq 4$ units for women and average frequency was $\geq 2$ days/week.

c $\geq 20$ minutes/once and $\geq 3$ times/week with rapid respiration or physical strain.

d Usual working schedule include evening or night work.

between work schedules and depressed mood (22). However, this association was not significant after adjusting for demographic factors such as age and gender in recent study result using the same cohort (13). In previous studies without significant association between shift work and depression, authors pointed out the possibility of underestimation due to healthy worker effect, overcorrection for effect modifiers such as work characteristics, job stress, or gender, and misclassification due to the large study sample size including various occupational groups $(13,23)$. The result of this study could also be underestimated due to
Table 2. The distribution of average working hours according to individual characteristics by gender. [SE=standard error]

\begin{tabular}{|c|c|c|c|c|c|c|}
\hline \multirow[t]{2}{*}{ Variables } & \multicolumn{2}{|c|}{ Male } & \multicolumn{2}{|c|}{ Female } & \multicolumn{2}{|c|}{ Total } \\
\hline & Mean & SE & Mean & SE & Mean & SE \\
\hline \multicolumn{7}{|l|}{ Age (years) } \\
\hline $15-19$ & 46.5 & 4.3 & 53.7 & 4.1 & 48.6 & 3.3 \\
\hline $20-39$ & 50.7 & 0.4 & 45.3 & 0.4 & 48.9 & 0.3 \\
\hline $40-54$ & 48.7 & 0.5 & 45.8 & 0.7 & 47.7 & 0.4 \\
\hline$\geq 55$ & 49.3 & 1.0 & 43.3 & 1.2 & 47.1 & 0.8 \\
\hline \multicolumn{7}{|l|}{ Marital status } \\
\hline Married & 49.7 & 0.3 & 44.8 & 0.5 & 48.3 & 0.3 \\
\hline Not married & 50.1 & 0.8 & 45.8 & 0.5 & 48.3 & 0.5 \\
\hline Others a & 49.9 & 1.6 & 46.5 & 1.2 & 47.7 & 1.0 \\
\hline \multicolumn{7}{|l|}{ Education } \\
\hline Elementary & 49.0 & 1.4 & 46.9 & 1.4 & 47.9 & 1.0 \\
\hline Middle & 51.9 & 1.3 & 45.6 & 1.2 & 49.2 & 0.9 \\
\hline High & 51.1 & 0.5 & 45.4 & 0.6 & 49.3 & 0.4 \\
\hline$\geq$ College & 48.4 & 0.4 & 44.4 & 0.4 & 47.2 & 0.3 \\
\hline \multicolumn{7}{|c|}{ Employment status } \\
\hline Regular & 50.2 & 0.3 & 46.0 & 0.4 & 48.9 & 0.3 \\
\hline Temporary & 52.2 & 1.1 & 44.7 & 0.8 & 48.4 & 0.8 \\
\hline Day laborer & 43.4 & 1.3 & 41.2 & 1.8 & 42.6 & 1.1 \\
\hline \multicolumn{7}{|c|}{ Current smoking } \\
\hline No & 49.1 & 0.4 & 45.0 & 0.4 & 47.1 & 0.3 \\
\hline Yes & 50.5 & 0.4 & 48.7 & 1.3 & 50.3 & 0.4 \\
\hline \multicolumn{7}{|c|}{ Problem drinking ${ }^{b}$} \\
\hline No & 49.4 & 0.4 & 45.1 & 0.4 & 47.9 & 0.3 \\
\hline Yes & 49.8 & 0.6 & 48.3 & 1.2 & 49.6 & 0.6 \\
\hline \multicolumn{7}{|l|}{ Exercise $^{c}$} \\
\hline No & 49.8 & 0.3 & 45.1 & 0.4 & 48.1 & 0.3 \\
\hline Yes & 49.9 & 0.6 & 46.4 & 0.9 & 48.9 & 0.5 \\
\hline \multicolumn{7}{|l|}{ Work schedule } \\
\hline Only daytime & 48.8 & 0.3 & 44.9 & 0.4 & 47.4 & 0.3 \\
\hline Shift worker ${ }^{d}$ & 53.9 & 0.9 & 46.8 & 1.3 & 51.7 & 0.8 \\
\hline \multicolumn{7}{|c|}{ Depressive symptom } \\
\hline No & 49.6 & 0.3 & 45.1 & 0.4 & 48.2 & 0.2 \\
\hline Yes & 51.9 & 1.2 & 46.5 & 0.9 & 49.2 & 0.8 \\
\hline Total & 49.8 & 0.3 & 45.3 & 0.4 & 48.3 & 0.2 \\
\hline
\end{tabular}

possible misclassification due to large sample size with various work characteristics, regardless of adjustment for employment status. Economical reward of shift work is another possible explanation for this negative result (24). It might be one of the specific reasons why Korean FTE worked longer hours, including night shifts. As a result, the difference in economic reward between shift and day workers could be very large.

This study has led to important implications for a policy change. The association between working hours and depressive symptomatology supports a recent policy decision of the Korean government to shorten working hours and increase public awareness of the relationship between long working hours and depression. We anticipate further research using representa- 
Table 3. The odds ratios and $95 \%$ confidence intervals of working hours on depressive symptom. [OR=0dds ratio; $95 \% \mathrm{Cl}=95 \%$ confidence interval]

\begin{tabular}{|c|c|c|c|c|c|c|c|c|c|}
\hline \multirow[t]{2}{*}{ Variables } & \multicolumn{3}{|c|}{ Model $1{ }^{\text {a }}$} & \multicolumn{3}{|c|}{ Model $2^{b}$} & \multicolumn{3}{|c|}{ Model $3^{c}$} \\
\hline & $\mathrm{OR}$ & $95 \% \mathrm{Cl}$ & $P$ for trend & $\mathrm{OR}$ & $95 \% \mathrm{Cl}$ & P for trend & $\mathrm{OR}$ & $95 \% \mathrm{Cl}$ & $\mathrm{P}$ for trend \\
\hline Work week (hours) & & & 0.0193 & & & 0.0039 & & & 0.0059 \\
\hline$<52$ & 1.00 & & & 1.00 & & & 1.00 & & \\
\hline $52-59$ & 1.23 & $0.85-1.79$ & & 1.23 & $0.82-1.85$ & & 1.19 & $0.77-1.85$ & \\
\hline$\geq 60$ & 1.46 & $1.12-1.90$ & & 1.63 & $1.22-2.17$ & & 1.62 & $1.20-2.18$ & \\
\hline Age (years) & 1.00 & $0.99-1.01$ & & 1.01 & $0.99-1.02$ & & 1.00 & $0.99-1.02$ & \\
\hline \multicolumn{10}{|l|}{ Gender } \\
\hline Men & 1.00 & & & 1.00 & & & 1.00 & & \\
\hline Women & 1.93 & $1.55-2.39$ & & 2.28 & $1.71-3.03$ & & 2.12 & $1.58-2.86$ & \\
\hline \multicolumn{10}{|l|}{ Marital status } \\
\hline Married & 1.00 & & & 1.00 & & & 1.00 & & \\
\hline Not married & 1.44 & $1.05-1.98$ & & 1.55 & $1.12-2.13$ & & 1.48 & $1.06-2.07$ & \\
\hline Others $^{d}$ & 2.25 & $1.89-3.16$ & & 2.52 & $1.71-3.71$ & & 2.65 & $1.76-3.97$ & \\
\hline \multicolumn{10}{|l|}{ Education } \\
\hline$\geq$ College & 1.00 & & & 1.00 & & & 1.00 & & \\
\hline High & 1.44 & $1.13-1.84$ & & 1.38 & $1.05-1.80$ & & 1.28 & $0.97-1.70$ & \\
\hline Middle & 1.49 & $0.97-2.29$ & & 1.53 & $0.98-2.38$ & & 1.45 & $0.91-2.32$ & \\
\hline$\leq$ Elementary & 1.87 & $1.23-2.86$ & & 1.85 & $1.14-2.98$ & & 1.80 & $1.08-2.98$ & \\
\hline \multicolumn{10}{|l|}{ Current smoking } \\
\hline No & & & & 1.00 & & & 1.00 & & \\
\hline Yes & & & & 1.39 & $1.03-1.86$ & & 1.38 & $1.01-1.90$ & \\
\hline \multicolumn{10}{|l|}{ Problem drinking $\mathrm{e}$} \\
\hline No & & & & 1.00 & & & 1.00 & & \\
\hline Yes & & & & 0.94 & $0.70-1.27$ & & 1.00 & $0.74-1.36$ & \\
\hline \multicolumn{10}{|l|}{ Exercise $^{f}$} \\
\hline No & & & & 1.00 & & & 1.00 & & \\
\hline Yes & & & & 0.86 & $0.66-1.23$ & & 0.83 & $0.63-1.10$ & \\
\hline \multicolumn{10}{|l|}{ Employment status } \\
\hline Regular & & & & & & & 1.00 & & \\
\hline Temporary & & & & & & & 1.24 & $0.86-1.80$ & \\
\hline Day laborer & & & & & & & 1.06 & $0.71-1.58$ & \\
\hline \multicolumn{10}{|l|}{ Working schedule } \\
\hline Only daytime & & & & & & & 1.00 & & \\
\hline Shift worker ${ }^{g}$ & & & & & & & 1.01 & $0.71-1.42$ & \\
\hline
\end{tabular}

a Adjusted for demographic factors such as age, gender, marital status, and education.

${ }^{\mathrm{b}}$ Adjusted for demographic factors and health behaviors such as current smoking, problem drinking, and exercise.

${ }^{c}$ Adjusted for demographic factors, health behaviors, and work characteristics such as employment status and working schedule.

a Widowed, separated, or divorced.

${ }^{e}$ Average amount in each kind of drinking was $\geq 6$ units for men and $\geq 4$ units for women and average frequency was $\geq 2$ days/week.

$\mathrm{i} \geq 20$ minutes/once and $\geq 3$ times/week with rapid respiration of breath or physical strain.

${ }^{9}$ Usually working from 14:00-24:00 hours, usually working from 21:00-08:00 hours the following day, regular rotating shift, 24-hour rotating shift, split shift, irregular rotating shift, or others.

tive data about the relationships between working hours and other health problems.

\section{References}

1. Van der Hulst M. Long workhours and health. Scand J Work Environ Health. 2003;29(3):171-88. http://dx.doi. org/10.5271/sjweh.720.

2. Caruso CC, Hitchcock EM, Dick RB, Russo JM, Schmit JM. Overtime and extended work shifts: recent findings on illnesses, injuries, and health behaviors. Cincinnati: National Institute for Occupational Safety and Health (NIOSH); 2004.
3. Artazcoz L, Cortès I, Escribà-Agüir V, Cascant L, Villegas R.. Understanding the relationship of long working hours with health status and health-related behaviors. J Epidemiol Community Health. 2009 Jul;63(7):521-7. http://dx.doi. org/10.1136/jech.2008.082123.

4. Caruso CC, Bushnell T, Eggerth D, Heitmann A, Kojola B, Newman K, et al. Long working hours, safety, and health: toward a National Research Agenda. Am J Ind Med. 2006 Nov;49(11):930-42. http://dx.doi.org/10.1002/ajim.20373.

5. Murray CJ, Lopez AD. Alternative projections of mortality and disability by cause 1990-2020: Global Burden of Disease Study. Lancet. 1997; 349:1498-504. http://dx.doi. org/10.1016/S0140-6736(96)07492-2.

6. Kessler RC, Greenberg PE, Mickelson KD, Meneades LM, 
Wang PS. The effects of chronic medical conditions on work loss and work cutback. J Occup Environ Med. 2001;43:218 25. http://dx.doi.org/10.1097/00043764-200103000-00009.

7. Kessler RC, Akiskal HS, Ames M, Birnbaum H, Greenberg P, Hirschfeld RM, Jin R, Merikangas KR, Simon GE, Wang PS. Prevalence and effects of mood disorders on work performance in a nationally representative sample of U.S. workers. Am J Psychiatry. 2006;163:1561-8. http://dx.doi.org/10.1176/appi. ajp.163.9.1561 .

8. Choi KS, Kang SK. Occupational psychiatric disorders in Korea. J Korean Med Sci. 2010 Dec;25(Suppl):S87-93. http:// dx.doi.org/10.3346/jkms.2010.25.S.S87.

9. Shields M. Long working hours and health. Health Rep. 1999 Autumn;11(2):33-48.

10. Nagashima S, Suwazono Y, Okubo Y, Uetani M, Kobayashi E, Kido $T$, et al. Working hours and mental and physical fatigue in Japanese workers. Occup Med (Lond). 2007 Sep;57(6):449 52. http://dx.doi.org/10.1093/occmed/kqm047.

11. Kleppa E, Sanne B, Tell GS. Working overtime is associated with anxiety and depression: the Hordaland Health Study. J Occup Environ Med. 2008 Jun;50(6):658-66. http://dx.doi. org/10.1097/JOM.0b013e3181734330.

12. Virtanen M, Ferrie JE, Singh-Manoux A, Shipley MJ, Stansfeld SA, Marmot MG, et al. Long working hours and symptoms of anxiety and depression: a 5-year follow-up of the Whitehall II study. Psychol Med. 2011;18:1-10.

13. Driesen K, Jansen NW, van Amelsvoort LG, Kant I. The mutual relationship between shift work and depressive complaints - a prospective cohort study. Scand J Work Environ Health. 2011;37(5):402-10. http://dx.doi.org/10.5271/ sjweh.3158.

14. Nakata A. Work hours, sleep sufficiency, and prevalence of depression among full-time employees: a community-based cross-sectional study. J Clin Psychiatry. 2011 May;72(5):60514. http://dx.doi.org/10.4088/JCP.10m06397gry.

15. Varma A, Marott JL, Stoltenberg CD, Wieclaw J, Kolstad HA, Bonde JP. With long hours of work, might depression then lurk? A nationwide prospective follow-up study among Danish senior medical consultants. Scand J Work Environ Health. 2012 Sep;38(5):418-26. http://dx.doi.org/10.5271/ sjweh.3268

16. OECD (2012). Hours worked, In: OECD Factbook 2011-12: Economic, Environmental and Social Statistics [Internet]. Paris: OECD Publishing; 2011 [cited 2011 Dec 7]. Available from: http://www.oecd-ilibrary.org/economics/oecdfactbook_18147364.

17. Lee S, McCann D, Messenger JC. Working time around the world; trends in working hours, law and policies in a global comparative perspective. Geneva: ILO; 2007. p. 45-53.

18. Ministry of Employment and Labor [Internet]. Chapter IV. Working Hours and Recess, In: Labor Standard Act. 2011. [cited 2011 October 31] Available from: http://www.moel.go.kr/ english/topic/laborlaw_view.jsp?idx=254\&tab=Standards.

19. Korea Center for Disease Control \& Prevention. Data analysis, In; Korea Health Statistics 2009 :Korea National Health and Nutrition Examination Survey (KNHANESIV-3). Seoul: Ministry of Health \& Welfare; 2010. p. 7-12.

20. Hartley L, Creed H, Gilroy P, Todd D [Internet]. Extended Working Hours Review. 2004. [cited 2001 Feb 4] Available from: http://www.commerce.wa.gov.au/labourrelations/ PDF/Publications/EWH_Final_27Feb04.pdf.

21. European Foundation for the Improvement of Living and Working Conditions [Internet]. Comparative analysis of working time in the European Union. 2010. [cited 2009 Nov 16] Dublin. http://www.eurofound.europa.eu/docs/ewco/ tn0803046s/tn0803046s.pdf.

22. Driesen K, Jansen NW, Kant I, Mohren DC, van Amelsvoort LG. Depressed mood in the working population: associations with work schedules and working hours. Chronobiol Int. 2010;27(5):1062-79. http://dx.doi.org/10.3109/07420528.2 010.489877 .

23. Bara AC, Arber S. Working shifts and mental health--findings from the British Household Panel Survey (1995-2005). Scand J Work Environ Health. 2009 Oct;35(5):361-7. http://dx.doi. org/10.5271/sjweh.1344.

24. Kim YH, Kim YM, Kim SH, Chang KO, Koo MJ, Lee NY. Workers' experiences in shift work. J Korean Acad Community Health Nurs. 2007;18(2):284-92. (Korean).

Received for publication: 4 June 2012 